Preface

\title{
Perspective on catalysis for sustainable energy and environmental technologies
}

The wealth created in the world over the last century can be said largely based on the easy access to economical fossil fuels. This would not be true for the energy and climate constrained world in the next century. As oil becomes more expensive and limited in supply and other fossil fuels face greater challenges in carbon emission reduction, the pressure is on governments and industries to develop cleaner energy sources and technologies to clean up pollution, improve energy efficiency and mitigate carbon emissions.

Catalysis is a critical process to the development of environmentally friendly and clean technologies, not only for energy but also for health, environment and in many other fields. Catalysis has played significant roles in many areas of sustainable development including alternative energy conversion, biodegradable chemicals, end of pipe pollution control, and cleaner production.

The Asia Pacific Conference on Sustainable Energy \& Environmental Technologies (APCSEET) provides a regular forum to showcase the research achievements in sustainable energy and environmental technologies in Asia and Pacific region. The inaugural APCSEET was held in Singapore in 1996, followed by the subsequent biennial conferences held in Australia (1998), Hong Kong (2000), Japan (2003), New Zealand (2005), Thailand (2007) and China (2009). This conference brought together scientists and engineers, and policy makers from governments, academias and industries to exchange ideas and discuss the latest developments in sustainable technologies for energy and environment. The 7th APCSEET received over 340 papers including 8 invited plenary and 16 keynote papers. The technical program particularly the plenary and keynote papers and invited talks emphasized the importance of the integration of knowledge creation and application with long-term trends and industrial needs. The papers provided good insights and interesting perspectives on the challenges, opportunities and solutions to energy and environmental sustainability issues.

This special issue presents selected papers from the conference pertinent to catalyst preparation and characterization, catalytic reactions and processes in energy and environmental applications. The papers have been subject to an initial screening process by the conference organisers and then a normal peer-review process. The following are some highlights as a general summary of the topics covered in this issue.

Catalysis has wide impact on clean energy production with low pollution and low carbon emissions. About 10 papers in this special issue deal with topics such as biomass combustion and gasification, thermal processing of coal and biomass, emission reduction, and hydrogen production from renewable sources.

There are 20 papers concerning environmental catalysis such as catalysts for exhaust emission control, deep desulfurization of gasoline and diesel and greenhouse gas mitigation technologies etc.

This special issue also presents 15 papers concerning sustainable chemical feedstock and cleaner production. For example, innovations in catalysts preparation and catalytic processes can often lead to high selectivity for target products, high conversion of feedstock, green production and high energy efficiency in the chemical and petrochemical processing industries.

One of the highlights of papers in this special issue is that the design and preparation of catalysts at the nanoscale is the key to improve activity and/or selectivity of certain reactions which are important to clean energy production. Nanostructured catalysts play important roles in hydrogen production, fuel cells, and energy storage and conversion processes. Both the chemical nature and nanostructure of the catalysts can be determining factors in influencing the catalyst activity, selectivity, and stability of supported catalysts.

We hope that readers will find the papers in this special issue of interest, usefulness and stimulation in their relevant research. We are appreciated to all authors and referees for their scientific contributions to the publication of this special issue. Last but not the least, we would like to express our gratitude to the editors of Catalysis Today, Professors Julian Ross and Yongdan Li for their strong support and encouragement, and the journal manager, Mary Harty for her wonderful assistance.

Zi-Feng Yan* State Key Laboratory for Heavy Oil Processing, PetroChina Key Laboratory of Catalysis, China University of Petroleum, Qingdao 266555, China

Zheng-Ping Hao Department of Environmental Nano-materials, Research Center for Eco-Environmental Sciences, Chinese Academy of Sciences, Beijing 100085, China

G.Q. (Max) Lu ARC Centre of Excellence for Functional Nanomaterials, Australian Institute for Bioengineering and Nanotechnology, The University of Queensland, Brisbane 4072, Australia

* Corresponding author. Tel.: +86 532 86981296; fax: +8653286981295. E-mail address: zfyancat@upc.edu.cn (Z.-F. Yan) Available online 16 October 2010 